\title{
A Study to Assess the Effectiveness of Hand Hygiene Technique among School Children in Maharashtra, India
}

\author{
Mayuri A. Mane ${ }^{1 *}$ and Sunita H. Tata ${ }^{2}$ \\ 1Krishna Institute of Nursing Sciences, Karad - 415539, Maharashtra, India; mayurim9595@gmail.com \\ ${ }^{2}$ Nursing Director, KH and MRC, Karad - 415539, Maharashtra, India
}

\begin{abstract}
Keeping kids healthy and clean it is important to teach the basic personal hygiene. It is extremely effective and inexpensive way to prevention of diarrhea and acute respiratory infections. The aim was to assess the effectiveness of hand hygiene technique demonstration on hand hygiene practices of primary school going children. Data was collected from the Rotary Shikshan Santha Malkapur Karad, Maharashtra, India. The study design used was one group pre-test, post-test design. 60 primary school going children aged 6 yrs-7 yrs were selected by simple random sampling technique. On the $1^{\text {st }}$ day, predemonstration test was conducted by using modified observational checklist and demonstration of hand hygiene technique was administered. After 7 days post-demonstration test was conducted. Descriptive and inferential statistics were used for data analysis. The result showed that the mean pre-demonstration value was 5.383 and mean post-demonstration value was 9.033 . The paired t' test value was 23.744 , $(\mathrm{p}<0.0001)$ showing a significant gain in the improvement of hand hygiene practice of primary school going children. Chi-square test shows that there was a significant association of predemonstration practice score of primary school going children with mothers' education $\left(\chi^{2}=16.436, p<0.05\right)$, father's education $\left(\chi^{2}=23.016, p<0.05\right)$. The study was concluded that the demonstration of hand hygiene technique regarding hand hygiene was effective in improving the practices of hand hygiene of primary school going children and thus administration of steps of hand hygiene technique was easy to understand.
\end{abstract}

Keywords: Effectiveness, Hand Hygiene Technique Demonstration, Primary School Children

\section{Introduction}

For maintaining health Hand Washing with Soap (HWWS) is effective, investing in HWWS is easy and minimal. For school children the practice is significant, who might suffer from more severe hygiene related diseases as compared to adults ${ }^{1}$. In the home and everyday life setting hand hygiene is central to prevent the spread of infectious diseases ${ }^{2}$.

School going children are spending more time in school and they are close contact with each other, sharing school materials everything from chairs to the desk, to crayons, to germs, and touching their faces. On surfaces, up to eight hours germs from sneeze and cough droplets can survive. So hand washing is an effective way to prevent the spread of common school illnesses like cold, pinkeye and flu and much more.

Teaching children hand washing is important to keep them clean and healthy. It is easy to teach step by step guiding to the child how to wash their hand properly. Especially teach the child to hand wash often, before eating, after blowing nose and after the use of the bathroom. As a matter of habit, it is very good idea to make sure washing hand becomes something automatically ${ }^{3}$.

For improvement of health and prevention of diseases (e.g., diarrhea and gastrointestinal infections) hand washing with soap is very important for school-age children, which helps to reduce the absenteeism due to illness ${ }^{1}$. 


\section{Objectives of the Study}

- To assess the pre-demonstration hand hygiene practices among the primary school going children.

- To evaluate the effectiveness of demonstration of hand hygiene technique among the primary school going children.

- To find the association between the pre-demonstration score with selected demographic variables.

\subsection{Assumption}

- Primary school going children are able to adapt the skill of hand washing technique.

- Demonstration of hand hygiene technique may helpful to improve hand hygiene practices among the Primary school going Children.

- Hand hygiene technique may help to improve their health and prevention of diseases like diarrhea, respiratory diseases.

\subsection{Hypothesis}

- H1: After hand washing techniques demonstration, Primary School going children will improve their hand washing practice.

- H2: There will be a significant association between pre-test score with selected demographic variables.

\section{Materials and Methods}

Descriptive evaluative approach and one group pretest, a post-test design was used to conduct the study. Administration of hand hygiene technique demonstration was the independent variable and a hand hygiene practice was the dependent variable. The study was conducted in Rotary Shikshan Santha, Malkapur, Karad, Maharashtra, India. 60 primary school going children under the age group of 6yrs - 7yrs were selected as a sample of the study by using simple random sampling. With the help of guide and experts, to assess the effectiveness of demonstration of hand hygiene technique on hand hygiene practices of primary school going children, modified observational checklist were prepared.

The research tools consists of two sections

Section A: Demographic variable - Age, sex, mother's education, and father's education, mother's occupation, father's occupation.
Section B: Administration of demonstration of hand hygiene technique.

\subsection{Instructions to Children}

- Instructed to children to keep clean handkerchief with them during the hand washing to dry hands.

- Instructed to keep nails round and short.

- 5 min was given to each child for hand washing.

\subsection{Steps of Hand Hygiene Technique}

- Wet hand with tap water.

- Apply appropriate soap on hand.

- Rub palm to palm 5 times.

- Rub right palm over the back of the left hand up to wrist level 5 times and vice versa.

- Rub palm to palm with finger interlaced.

- Backs of fingers to opposing palms with fingers interlocked.

- Wash thumb of each hand separately using a rotating movement.

- Rub the tips of fingers against the opposite palm using a circular motion.

- Rinse hand thoroughly under running water to remove all traces of soap.

- Thoroughly dry hands and wrists with a handkerchief.

Section C: Modified observational checklist.

\subsection{Sampling Criteria}

\subsubsection{Inclusion Criteria}

- Who were willing to participate in the study?

- All the children whose age group was between 6 yrs-7 yrs.

- Children who were present in the school at the time of data collection.

\subsubsection{Exclusion Criteria}

- Children those who were absent at the time of data collection.

\section{Method of Data Collection}

To conduct the study the permission was obtained from the institutional ethical committee of Krishna Institute of Medical Sciences, Karad on 20/1/2016 and the Principal 
of Rotary Shikshan Santha, Malkapur, Karad on 28/09/16. Informed consent and explanation of demonstration of hand hygiene technique were obtained from parents. Daily 20 children for 1 hour were assessed for hand hygiene practices. First, 10 children were assessed then next 10 children and 5 minutes had given for each child for hand hygiene and intervention of demonstration of hand hygiene was given. After pretest, administration of demonstration of hand hygiene technique was given by step by step and after 7 days post-test was taken by using same observational checklist.

\subsection{Plan for Data Analysis}

- The data obtained was analyzed by descriptive and inferential statistics by considering the objectives of the study. Experts in the field nursing and statistics were consulted for the plan of the data analysis.

The investigator planned to analyze the data in the following manner.

- Organize data on the master sheet.

- Computed frequency, percentage, mean, standard deviation, and range to describe the data.

- Classify practices score as follows

- Good (7-10) - above [Mean (M) + Standard deviation (SD)]
- Average (5-6) - between [(M+SD) and (M-SD)]

- Poor (0-4)-Below [M-SD]

- Use inferential statistics to draw the conclusions.

\subsection{The Data Findings have been Organized and Presented under the Following Section}

- Section A: it deals with the analysis of sociodemographic variables of the samples.

- Section B: it deals with the analysis of data related to practice score regarding pre-demonstration score and post-demonstration score under percentage distribution, mean, median, standard deviation, range, mean difference and 't' value.

- Section C: It deals with the analysis of data to find out the association between pre-demonstration score with selected socio-demographic variables.

\section{Results}

Section A: Distribution of children according to demographic variables.

The data presented in Table 1 reveals the distribution of according to demographic variables.

Table 1. Frequency and percentage distribution of children according to demographic variables

\begin{tabular}{|c|c|c|c|c|}
\hline Sr. No & Characteristics & Category & Frequency $(\mathrm{N})$ & Percentage (\%) \\
\hline \multirow[t]{2}{*}{1.} & \multirow[t]{2}{*}{ Age (Yrs.) } & $6 y r s$ & 33 & $55 \%$ \\
\hline & & $7 y$ yrs & 27 & $45 \%$ \\
\hline \multirow[t]{2}{*}{2.} & \multirow[t]{2}{*}{ Sex } & Male & 35 & $58 \%$ \\
\hline & & Female & 25 & $42 \%$ \\
\hline \multirow[t]{5}{*}{3.} & \multirow[t]{5}{*}{ Mother's education } & Illiterate & 2 & $3 \%$ \\
\hline & & Primary education & 10 & $17 \%$ \\
\hline & & Secondary education & 12 & $20 \%$ \\
\hline & & Higher Secondary education & 22 & $37 \%$ \\
\hline & & Post-graduate and above & 14 & $23 \%$ \\
\hline \multirow[t]{5}{*}{4.} & \multirow[t]{5}{*}{ Father's education } & Illiterate & 2 & $3 \%$ \\
\hline & & \begin{tabular}{|l|} 
Primary education \\
\end{tabular} & 15 & $25 \%$ \\
\hline & & Secondary education & 8 & $14 \%$ \\
\hline & & Higher Secondary education & 20 & $33 \%$ \\
\hline & & Post-graduate and above & 15 & $25 \%$ \\
\hline \multirow[t]{5}{*}{5.} & \multirow[t]{5}{*}{ Mother's occupation } & Housewife & 30 & $50 \%$ \\
\hline & & Business & 3 & $5 \%$ \\
\hline & & \begin{tabular}{|l|} 
Service \\
\end{tabular} & 15 & $25 \%$ \\
\hline & & Farmer & 2 & $3 \%$ \\
\hline & & Any Other & 10 & $17 \%$ \\
\hline \multirow[t]{5}{*}{6.} & \multirow[t]{5}{*}{ Father's occupation } & Daily wages & 11 & $18 \%$ \\
\hline & & Business & 13 & $22 \%$ \\
\hline & & \begin{tabular}{|l|} 
Service \\
\end{tabular} & 27 & $45 \%$ \\
\hline & & Farmer & 9 & $15 \%$ \\
\hline & & Any Other & 0 & $0 \%$ \\
\hline
\end{tabular}


- A maximum number of 33(55\%) of primary school going children, belonged to the age group of 6yrs. and 27(45\%) were in 7 yrs. And 35 (58\%) was males and minimum 25(42\%) were females.

- The majority of the mothers $10(17 \%)$ education status belonged to primary and $12(20 \%)$ in secondary education, 22(37\%) had higher secondary education, $14(23 \%)$ had postgraduate and above and minimum $2(3 \%)$ were illiterate.

- The majority of father's education $15(25 \%)$ belong to primary education, $8(14 \%)$ had secondary education, 20(33\%) had higher secondary education, 15(25\%) had postgraduate and above and maximum 2(3\%) were illiterate.

- The majority of mother's occupation $30(50 \%)$ were the housewife, $15(25 \%)$ were in service, $10(17 \%)$ were in any other, $3(5 \%)$ were in business, minimum $2(3 \%)$ were the farmer.

- The majority of father's occupation $27(45 \%)$ had service, $13(22 \%)$ had the business, $11(18 \%)$ had daily wages, minimum $9(15 \%)$ were the farmer, none of them $0(0 \%)$ were in any other.

Section B: It deals with the analysis of data related to practice score regarding pre-demonstration score and post-demonstration score under percentage distribution, mean, median, standard deviation, range, mean difference and $t^{\prime}$ value.

Table 2 Reveals that in pretest majority 54(90\%) had average practice, $6(10 \%)$ had a good practice and $0(0 \%)$ none of them had poor practice. Whereas in the post-test majority $60(100 \%)$ had a good practice and none of them had average and poor practice regarding hand hygiene practices before and after the demonstration.

Figure 1 reveals practice regarding hand hygiene practices pre- and post-demonstration of 60 observations with the difference means of -3.650 . SD of -0.1111 and the computed t' test statistic value is 23.744 . Since the p-value for the test was less than $0.05 . \mathrm{H}_{1}$ was accepted. i.e., there was a significant difference between the pretest and posttest practice score and mean posttest practice score was higher than their mean pretest practice at 0.05 level of significance. It was shown that the demonstration of hand hygiene technique was effective in improving practice regarding hand hygiene pre and post.

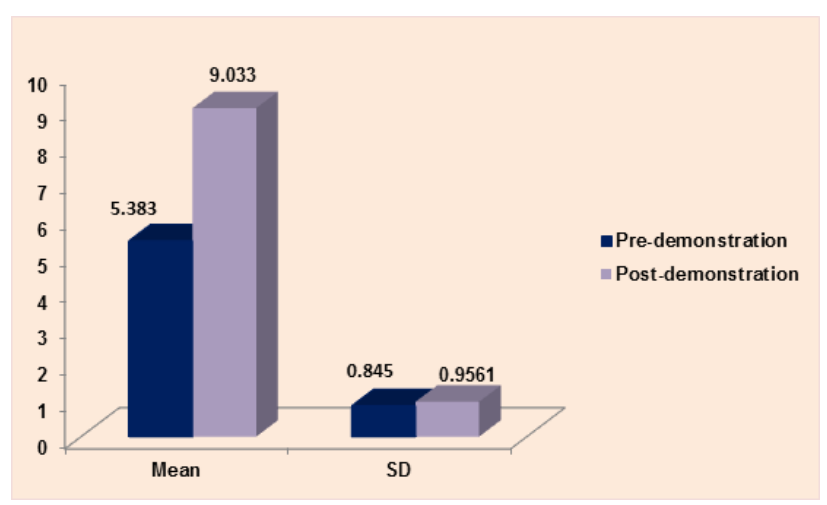

Figure 1. Mean, standard deviation and range of practice score of primary school going children regarding hand hygiene $(\mathrm{N}=60)$.

- Section C: It deals with the analysis of data to find out the association between pre-demonstration score with selected socio-demographic variables.

Table 3 Reveals association between demographic variables and pre-demonstration score

There was significant association between predemonstration practice score and demographic variable such as Mother's education and father's education as $\mathrm{P}<$ 0.05 and there was no significant association between predemonstration practice score such as age, sex, mother's and father's occupation as $\mathrm{P}>0.05$.

Table 2. Distribution of frequency and percentage practice score of primary school going children regarding hand hygiene $(\mathrm{N}=60)$

\begin{tabular}{|l|c|c|c|c|c|c|}
\hline Score & Good & Average & Poor & Chi-square & P-value & Inference \\
\hline Pre-test & $6(10 \%)$ & $54(90 \%)$ & $0(0 \%)$ & 98.182 & 0.0001 & Significant \\
\hline Post-test & $60(100 \%)$ & $0(0 \%)$ & $0(0 \%)$ & & & \\
\hline
\end{tabular}


Table 3. Association between pre-demonstration practices on hand hygiene with selected demographic variables $(\mathrm{N}=60)$

\begin{tabular}{|c|c|c|c|c|c|c|}
\hline \multirow[t]{2}{*}{ Study Variables } & \multicolumn{3}{|c|}{ Pre Demonstration } & \multirow[t]{2}{*}{ Chi-square } & \multirow[t]{2}{*}{ P-value } & \multirow[t]{2}{*}{ Inference } \\
\hline & Good & Average & Poor & & & \\
\hline \multicolumn{7}{|l|}{ Age } \\
\hline 6 Yrs. & 1 & 32 & 0 & \multirow[t]{2}{*}{4.589} & \multirow[t]{2}{*}{0.1008} & \multirow[t]{2}{*}{ NS } \\
\hline 7 Yrs. & 0 & 24 & 3 & & & \\
\hline \multicolumn{7}{|l|}{ Sex } \\
\hline Male & 0 & 30 & 5 & \multirow[t]{2}{*}{1.486} & \multirow[t]{2}{*}{0.4758} & \multirow[t]{2}{*}{ NS } \\
\hline Female & 1 & 20 & 4 & & & \\
\hline \multicolumn{7}{|l|}{ Mother's Education } \\
\hline Primary Education & 1 & 8 & 1 & \multirow[t]{5}{*}{16.436} & \multirow[t]{5}{*}{0.0365} & \multirow[t]{5}{*}{$\mathrm{S}$} \\
\hline Secondary Education & 2 & 10 & 0 & & & \\
\hline Higher Secondary Education & 1 & 18 & 3 & & & \\
\hline Post Graduate \& above & 1 & 8 & 5 & & & \\
\hline Illiterate & 0 & 0 & 2 & & & \\
\hline \multicolumn{7}{|l|}{ Father's Education } \\
\hline Primary Education & 3 & 11 & 1 & \multirow[t]{5}{*}{23.016} & \multirow[t]{5}{*}{0.0033} & \multirow[t]{5}{*}{$S$} \\
\hline Secondary Education & 2 & 6 & 0 & & & \\
\hline Higher Secondary Education & 0 & 17 & 3 & & & \\
\hline Post Graduate \& above & 0 & 9 & 6 & & & \\
\hline Illiterate & 0 & 0 & 2 & & & \\
\hline \multicolumn{7}{|l|}{ Mothers Occupation } \\
\hline Housewife & 2 & 19 & 9 & \multirow[t]{5}{*}{12.16} & \multirow[t]{5}{*}{0.1442} & \multirow[t]{5}{*}{ NS } \\
\hline Service & 3 & 4 & 8 & & & \\
\hline Farmer & 0 & 1 & 1 & & & \\
\hline Business & 0 & 0 & 3 & & & \\
\hline Any other & 0 & 6 & 4 & & & \\
\hline \multicolumn{7}{|l|}{ Fathers Occupation } \\
\hline Farmer & 1 & 1 & 7 & \multirow[t]{5}{*}{10.307} & \multirow[t]{5}{*}{0.1123} & \multirow[t]{5}{*}{ NS } \\
\hline Service & 0 & 12 & 15 & & & \\
\hline Business & 0 & 6 & 7 & & & \\
\hline daily wages & 1 & 1 & 9 & & & \\
\hline Any other & 0 & 0 & 0 & & & \\
\hline
\end{tabular}

\section{Discussion}

The study was conducted to assess the effectiveness hand hygiene technique demonstration on hand hygiene practices among primary school going children. The primary aim of the study was to assess the effectiveness of hand hygiene technique demonstration on hand hygiene practices. The results showed that the demonstration of hand hygiene technique was simple, inexpensive and effective as the paired t' test value was $23.744,(\mathrm{p}<0.001))$ showing the significant difference between the predemonstration score of primary school going children and post-demonstration score.

This research was conducted in the educational year of 2012-2013 in a primary school, among 185 primary school students from grade 6 to 8 at Kepez, Canakkale, Turkey, to improve hand hygiene of students. The result was of these participants, $32.3 \%$ were from grade $6,32.3 \%$ from grade 7 , and $35.4 \%$ from grade $8 ; 98.1 \%$ students were living in Kepez and 1.9\% were living in the village. A statistically significant difference was detected between the first practice, which was made before training, and the second and third practices, which were made after training, in terms of hand washing skill development ( $\mathrm{p}$ $<0.001)$. After the training, hand-washing skill scores showed a significant increase than before-training skill scores in both female and male students $(\mathrm{p}<0.001)^{4}$. 
Another similar cross-sectional observational study was conducted among school going children (6th, 7th \& 8th standard) of two rural government high school involving all 168 students in rural Government Schools of Nalgonda, Andhra Pradesh. The result was revealed that the maternal and paternal literacy rates were $50.6 \%$ and $68.5 \%$ respectively and even among literate mothers, the majority (30.9\%) was studied only up to primary level. It is significantly associated with the knowledge of students regarding hand hygiene $(\mathrm{p}<0.05)^{5}$.

\section{Conclusion}

The present study concludes that post demonstration practice score showed significant difference than the predemonstration practice score, which is a net benefit due to the effectiveness of demonstration of hand hygiene was simple, inexpensive and effective to improve children's knowledge and practices regarding hand hygiene.

\section{References}

1. Xuan LT, Hoat L. Handwashing among schoolchildren in an ethnically diverse population in northern rural Vietnam. Global Health Action. 2013; 6(1):18869. DOI: 10.3402/gha. v6i0.18869. Crossref

2. Bloomfield SF, Aiello AE, Cookson B, O'Boyle C, Larson EL. The effectiveness of hand hygiene procedures in reducing the risks of infections in home and community settings including hand washing and alcohol-based hand sanitizers. American Journal of Infection Control. 2007 Dec; 35(10 SUPPL. 1). DOI: 10.1016/j.ajic.2007.07.001. Crossref

3. Available from: Crossref

4. Cevizci S, Uludag A, Topaloglu N, Babaoglu U, Celik M, Bakar C. Developing students' hand hygiene behaviors in a primary school from Turkey: A school-based health education study. International Journal of Medical Science and Public Health. 2015; 4(2):155. Crossref

5. Takalkar A, Nirgude A, Naik P, Prasad VG, Reshmi SS. Hand hygiene: Perception and practices of school going children from rural government schools of Nalgonda, Andhra Pradesh. Int J Med Health Sci. 2013 Apr; 2(2):154-60. 